\title{
Turismo de observação de aves no Chaco: oportunidades e desafios ao Corredor Bioceânico, segmento Brasil / Paraguai
}

\author{
Birdwatching in Chaco: Opportunities and challenges to the Bioceanic Highroad \\ Crossing, Brazil / Paraguay segment
}

\author{
Turismo de observación de aves en el Chaco: oportunidades y desafíos en \\ Carretera Bioceánica, segmento Brasil / Paraguai
}

\author{
Simone Mamede ${ }^{1}$ \\ Maristela Benites ${ }^{2}$ \\ Alberto Esquivel $^{3}$ \\ Robert Clay ${ }^{4}$ \\ Geancarlo de Lima Merighi ${ }^{5}$ \\ Cleber José Rodrigues Alho ${ }^{1}$
}

Recebido em 10/02/2019; revisado e aprovado em 24/03/2019; aceito em 05/06/2019

DOI: http://dx.doi.org/10.20435/inter.v20iespecial.2386

\begin{abstract}
Resumo: A região de fronteira entre Brasil e Paraguai, no estado de Mato Grosso do Sul, encontra-se no centro de um dos Corredores Bioceânicos propostos e contempla áreas naturais de Chaco e Pantanal com exuberante biodiversidade. $\mathrm{O}$ ecoturismo tem na biodiversidade sua principal fonte de insumos, onde se destaca o turismo de observação de aves. Além de conectar territórios para viabilizar uma cadeia produtiva específica, o corredor logístico pode integrar pessoas e grupos sociais, e criar novas oportunidades de valorização dos ambientes naturais por meio do ecoturismo. O objetivo deste trabalho é propor roteiros integrados para o turismo de observação de aves na fronteira entre Brasil e Paraguai como estratégia de conservação da biodiversidade, inclusão social, dinamização econômica e valorização cultural das comunidades localizadas nos territórios de influência do Corredor Bioceânico. O trabalho foi desenvolvido entre 2002 e 2018 em Porto Murtinho (Brasil), Carmelo Peralta, departamento de Alto Paraguay, Concepción, Presidente Hayes e Boquerón (Paraguai). Foram identificados 10 potenciais roteiros para o turismo de observação de aves, dos quais, cinco encontram-se em Porto Murtinho, dois binacionais (Brasil/Paraguai), e outros três no Paraguai. Os roteiros envolvem locais com alta diversidade de aves: Parque Natural Municipal da Cachoeira do Apa, Parque Nacional Defensores del Chaco, Parque Nacional Médanos del Chaco, além de Reservas Privadas e a Reserva da Biosfera do Chaco no Paraguai. Ao todo, somam-se mais de 400 espécies de aves, entre endêmicas, migratórias, raras e ameaçadas. Esse segmento turístico representa um dos diversos modelos para o desenvolvimento sustentável da região do Corredor Bioceânico. Além disso, a proposta de roteiros integrados de birdwatching no Chaco reflete o potencial transfronteiriço do segmento e pode estimular a melhoria dos destinos, a geração de renda, a identificação de novos produtos e ampliar a qualidade da experiência do turista observador.
\end{abstract}

Palavras-chave: Birdwatching; Porto Murtinho; roteiro integrado; sustentabilidade; conservação socioambiental.

Abstract: The border region between the state of Mato Grosso do Sul (Brazil) and Alto Paraguay department (Paraguay) is at the center of a proposed Bi-oceanic Transport Highroad Crossing. In addition to connecting territories to facilitate more efficient production and access to markets, the transport corridor can integrate people and social groups and create new opportunities to value the natural environments through ecotourism. As an ecotone between the Pantanal and Chaco, the border region holds an exuberant biodiversity typical of both ecoregions, and consequently significant potential for ecotourism. The objective of the current work is to propose integrated itineraries for birdwatching tourism in the border region between Brazil and

\footnotetext{
${ }^{1}$ A Universidade para o Desenvolvimento do Estado e da Região do Pantanal (UNIDERP), Campo Grande, Mato Grosso do Sul, Brasil.

2 Universidade Estadual de Mato Grosso do Sul (UEMS), Campo Grande, Mato Grosso do Sul, Brasil.

${ }^{3}$ World Wildlife Fund, Asunción, Paraguay.

${ }^{4}$ Oficina Ejecutiva de la Red Hemisférica de Reservas para Aves Playeras, Paraguay.

${ }^{5}$ Fundação de Turismo de Mato Grosso do Sul, Campo Grande, Mato Grosso do Sul, Brasil.
} 
Paraguay, as a strategy for biodiversity conservation, social inclusion, economic diversification and cultural valorization of communities located in the territories influenced by the Bi-oceanic Highroad Crossing. The work was undertaken between 2002 and 2018 in Porto Murtinho (Mato Grosso do Sul, Brazil) and Carmelo Peralta and additional areas in the departments of Alto Paraguay, Concepción, Presidente Hayes and Boquerón (Paraguay). Ten potential itineraries for bird-watching tourism were identified, of which five are in Porto Murtinho; two binational and three others in Paraguay. The itineraries involve sites with high diversity of birds: Cachoeira do Apa Municipal Natural Park, Defensores del Chaco National Park, Medanos del Chaco National Park, as well as Private Reserves and the Chaco Biosphere Reserve in Paraguay. Altogether, more than 400 bird species are included, among them endemic, migratory, rare and endangered species. This ecotourism sector represents one of several models for the sustainable development of the Bi-oceanic Highroad Crossing region. In addition, the proposal for integrated birdwatching in the Chaco reflects the transboundary potential of the sector and can enable the improvement of destinations, income generation, identification of new products and the quality of the birdwatcher experience.

Keywords: Birdwatching; Porto Murtinho; integrated road map; sustainability; socio-environmental conservation.

Resumen: La región de frontera entre Brasil y Paraguay, en el departamento de Mato Grosso do Sul y el Departamento de Alto Paraguay, se encuentra en el centro de una de las Rutas Bioceánicas propuestas y contempla áreas naturales del Chaco y Pantanal con exuberante biodiversidad. El ecoturismo tiene como principal fuente de insumos la biodiversidad, siendo el turismo de observación de aves uno de los rubros con mayor crecimiento. Además de conectar territorios para viabilizar una cadena productiva restringida, el corredor logístico puede integrar personas y grupos sociales, a fin de valorar los ambientes naturales por medio del ecoturismo. El objetivo de este trabajo es proponer itinerarios integrados para el turismo de observación de aves en la frontera entre Brasil y Paraguay, como estrategia de conservación de la biodiversidad, inclusión social, dinamización económica y valorización cultural de las comunidades ubicadas en los territorios de influencia de la ruta bioceánica. El trabajo fue desarrollado entre 2002 y 2018 en Porto Murtinho (Brasil), Carmelo Peralta, y los departamentos de Alto Paraguay, Concepción, Presidente Hayes y Boquerón (Paraguay). Se identificaron 10 posibles itinerarios para el turismo de observación de aves, de los cuales cinco se encuentran en Porto Murtinho, dos binacionales y otros tres en Paraguay. Los itinerarios involucran lugares con alta diversidad de aves: Parque Natural Municipal da Cachoeira do Apa, Parque Nacional Defensores del Chaco, Parque Nacional Médanos del Chaco, además de Reservas Privadas y la Reserva de la Biosfera del Chaco en Paraguay. En total, se suman más de 400 especies de aves, entre endémicas, migratorias, raras y amenazadas. Este segmento turístico representa uno de los diversos modelos para el desarrollo sostenible de la región de la Ruta Bioceánica. Además, la propuesta de itinerarios integrados de birdwatching en Chaco refleja el potencial transfronterizo del segmento y puede posibilitar la mejora de los destinos, la generación de ingresos, la identificación de nuevos productos y la calidad de la experiencia del turista observador.

Palabras-clave: Birdwatching; Porto Murtinho; itinerario integrado; sostenibilidad; conservación socioambiental.

\section{CONTEXTUALIZAÇÃO GERAL SOBRE AS IMPLICAÇÕES DE UM CORREDOR BIOCEÂNICO NO PANTANAL E CHACO}

Há várias décadas a região de fronteira entre Brasil e Paraguai vem alimentando a expectativa de servir de ligação entre os portos logísticos do Oceano Atlântico e do Pacífico. Nos últimos anos, com o crescimento da produção de commodities, principalmente soja, e em resposta às demandas do continente asiático, a concretização de uma rota que otimize o escoamento da produção agrícola e de outros produtos aos países asiáticos, como a China, o Japão e a Índia, parece estar mais próxima. O Brasil é um dos principais exportadores mundiais de soja e a região Centro-Oeste é a que primeiramente se destaca nesse panorama. No entanto, a logística de transporte, desde os locais de produção até os portos por onde é exportada, tem sido apontada como o principal entrave à competitividade da soja produzida no Brasil (SILVA et al., 2011). Um Corredor Bioceânico, cujo traçado corta o estado do Mato Grosso do Sul tem se mostrado viável no sentido de reduzir a distância de 8 para 2 mil quilômetros.

Há várias propostas de corredores no continente sul-americano com metas de otimização logística e vantagens econômicas. Desse modo, o projeto de Corredor Rodoviário Bioceânico 
analisado neste trabalho inicia-se no Brasil e, no Mato Grosso do Sul, Porto Murtinho é o município fronteiriço com o Paraguai de onde partirá o transporte logístico rodoviário com destino final nos dois portos localizados ao norte do Chile, os terminais portuários de Antofagasta, Mejillones e Iquique. O Corredor tem por objetivo integrar Brasil, Paraguai, Argentina e Chile.

Numa análise dos fatores socioculturais, econômicos e ambientais produtores do espaço territorial de Porto Murtinho, poder-se-ia supor que as transformações previstas justificassem o desenvolvimento almejado. No entanto, há múltiplas faces desse cenário que precisam ser consideradas e balizadas sob a ótica da sustentabilidade.

Um dos aspectos diz respeito às ecorregiões que esse território compreende. Porto Murtinho (Brasil) e Carmelo Peralta (Paraguai) integram a maior planície continental alagável do planeta, o Pantanal (porção sul) e o Chaco úmido (extremo leste do Chaco sul-americano). Considera-se Porto Murtinho como o único município brasileiro que apresenta evidências florísticas expressivas do Chaco (PRADO, 1993). Segundo Silva e Caputo (2010), a vegetação chaquenha no Brasil se distribui no Pantanal, nas sub-regiões de Porto Murtinho, Nabileque, Paraguai, Abobral e Miranda, com maior concentração, entretanto, nas sub-regiões de Porto Murtinho e do Nabileque, ocupando 40,5\% e 82,6\% de suas áreas, respectivamente.

Outro fator relevante a se considerar é que se trata de área inundável periodicamente pelos pulsos de inundação do Rio Paraguai. Desse modo, a rodovia BR-267, por onde passarão veículos de transporte de cargas pesadas, atravessa vários ambientes alagáveis que servem de habitat para várias espécies. O movimento da fauna nesses locais é frequente, sendo comum o avistamento de animais que se deslocam pela rodovia para alcançarem outros habitat, momento em que se tornam vítimas fáceis de atropelamentos por veículos automotores. Ainda que atualmente o tráfego não seja intenso, se comparado ao pretenso corredor logístico, é possível encontrar uma variedade de animais atropelados, desde pequenos vertebrados como anfíbios, répteis e aves, até mamíferos de grande porte como o tamanduá-bandeira, o cervo-do-pantanal, a anta e as onças parda e pintada (MAMEDE et al., 2008). Em períodos de enchente do Rio Paraguai aumenta a movimentação desses animais em busca de refúgio, ampliando, consequentemente, a sua vulnerabilidade.

Característica marcante do ponto de vista socioeconômico é que Porto Murtinho experimentou desenvolvimento econômico expressivo desde a sua criação, indo do apogeu à decadência em três fases econômicas, isto é, da erva-mate (Ilex paraguariensis), do tanino (resina vegetal extraída do quebracho-vermelho Schinopsis balansae) e, mais recentemente, do turismo de pesca. A pecuária é o ciclo econômico mais estável na região e também de maior duração, visto ser referenciado historicamente desde o século XIX. A cultura murtinhense, por sua vez, está sintonizada à materialidade regional e se destaca por estar integrada às práticas culturais do Paraguai. O idioma é uma junção e sobreposição da língua portuguesa, do guarani e do espanhol (castelhano), evidenciando novamente a influência paraguaia.

Com a implantação do Corredor Bioceânico as transformações devem acarretar novas formas de produção do espaço geográfico, muitas das quais não experimentadas pelas populações residentes nesses países. Portanto, o momento é oportuno para se apontar propostas sustentáveis alinhadas às potencialidades naturais da região e que não acarretem erosão cultural, mas que incluam equanimemente as populações e ofereçam oportunidades de desenvolvimento nos seus múltiplos aspectos. 


\subsection{As potencialidades do ecoturismo e do turismo de observação de aves na fronteira entre Brasil e Paraguai}

O segmento do turístico que vem crescendo expressivamente e ganhando notoriedade mundial é o ecoturismo, do qual o turismo de observação de aves é um dos mais destacáveis. Em 2016, nos EUA, mais de 86 milhões de pessoas - quase um terço da população, entre jovens e adultos maiores de 16 anos, estiveram envolvidas com a observação de vida selvagem, das quais 45,1 milhões eram observadores de aves, os chamados birdwatchers (U.S. FISH; WILDLIFE SERVICE, 2018). O público total de observadores de vida selvagem investiu 75,9 bilhões de dólares em suas atividades.

Se por um lado o turismo se constitui em atividade lucrativa em seus termos, não deve ser ignorado como estratégia de difusão e de proteção do patrimônio natural e cultural de determinado território se, fundamentalmente, estiver alinhado aos princípios norteadores do ecoturismo, sintetizados basicamente em respeito aos bens naturais, às comunidades receptoras e disposição à mudança de atitudes frente ao ambiente. Ainda que utilizada pelo turismo, a natureza não deve ser vista e assimilada como simples mercadoria. Se assim o for, corre-se o risco de se propalar a espetacularização da natureza (RIBEIRO, 2018) e o exercício do turismo predatório disfarçado de ecoturismo, desprovido de princípios éticos, critérios, sensibilidade e responsabilidade.

O termo birdwatching compreende um conjunto de práticas não-consuntivas relacionadas às aves, tais como observar aves em casa e imediações, fotografar aves, apreciar o canto por elas emitido, viajar com a finalidade de observação de aves, elaborar listas das espécies observadas, monitorar ninhos, proteger habitats utilizados pelas aves e envolver-se em ações de salvamento e proteção das espécies (COLE; SCOTT, 1999; COOPER; SMITH, 2010; KJOLSROD, 2019). Portanto, observar aves representa uma forma de lazer e entretenimento baseados na natureza e, claramente, expressa o valor da biodiversidade aplicado ao contexto social e às práticas culturais.

Nessa região em análise confluem elementos fitogeográficos do Chaco, do Cerrado e de matas estacionais e, em associação às condições de enchentes sazonais do Rio Paraguai, tornam os ambientes favoráveis com nichos disponíveis a uma grande diversidade de espécies de aves. Populações vigorosas de aves aquáticas, como tuiuiús, cabeças-secas, garças e outras espécies, podem ser avistadas em períodos específicos do ano, atestando a alta produtividade ecológica regional e a intensidade dinâmica das redes tróficas. Em um final de semana, por exemplo, a depender do interesse e da disposição do observador, é possível avistar mais de 200 espécies, com deslocamentos não extensivos a $100 \mathrm{~km}$. Além disso, como as aves estão presentes no cotidiano dessas comunidades a indicação de onde encontrar determinadas espécies ou locais propícios ao avistamento são logo reconhecidos e apontados pelos moradores.

Em análise transfronteiriça, as aves do Chaco exercem grande fascínio nas populações locais, o que levou, ao longo de gerações, à criação e propagação de muitas lendas associadas a esses animais e agregou alta riqueza sociolinguística regional. Assim, o conhecimento sobre a riqueza de aves, somado à riqueza sociocultural, podem favorecer tanto a pesquisa científica, o turismo sustentável, a educação, quanto a autoestima das comunidades residentes.

Nos últimos anos têm-se ampliado os esforços de pesquisadores em estudos da avifauna dessa região, fato que se verifica com a frequente atualização das espécies catalogadas (TUBELIS; TOMAS, 2003; ZYSKOWSKI et al., 2003; GUYRA PARAGUAI, 2004; STRAUBE et al. , 2006a; STRAUBE 
et al., 2006b; BENITES et al., 2017). As listas de espécies representam fontes de pesquisa e importantes ferramentas de suporte ao turismo de birdwatching.

\subsection{Políticas de conservação do Chaco}

A região do Chaco no Brasil tem sido submetida a acelerado processo de conversão de habitat naturais para pastagens exóticas e expansão da pecuária (SILVA et al., 2008), sendo as espécies vegetais nativas fatalmente destinadas ao abastecimento de carvoarias e os fragmentos também ficam suscetíveis a incêndios florestais e outras formas de degradação. Porto Murtinho, mesmo sendo o segundo maior município em extensão territorial de Mato Grosso do Sul, com 1.773.500 hectares, detém de apenas 60.907,95 hectares de área protegida na forma de unidades de conservação, ou seja, não atinge $4 \%$ do território. A maior unidade de conservação se refere a uma Área de Proteção Ambiental (APA) do Rio Perdido, com 36.145,59 hectares. 0 Sistema Nacional de Unidades de Conservação classifica as APAs no grupo de unidades de uso sustentável. No entanto, essa categoria (APA) tem demonstrado baixa efetividade de conservação e, além disso, a APA do Rio Perdido não inclui remanescentes de Chaco.

No Chaco paraguaio existem sete áreas protegidas de domínio público, além da Reserva da Biosfera do Chaco e reservas privadas, as quais têm por finalidade a proteção da biodiversidade dessa importante ecorregião. As áreas protegidas no Paraguai são extensas, cobrindo um território importante. No entanto, ainda há pouca presença de guarda-parques, o que torna muito baixo o controle exercido. Além dos Parques Nacionais Defensores del Chaco, Médanos del Chaco e Teniente Enciso, existem outras áreas protegidas, como o Monumento Natural Cerro Chovoreca, o Parque Nacional Tinfunqué e o Parque Nacional Río Negro. No entanto, a regularização fundiária dessas áreas ainda não está totalmente definida, permanecendo como áreas protegidas somente no papel. O fortalecimento das áreas protegidas, por meio de maior investimento em recursos humanos, bem como a regularização das que ainda estão sem definição legal, deve ser uma prioridade para a conservação, dado o alto índice de desmatamento sofrido atualmente pelo Chaco paraguaio (BAUMANN et al., 2017).

A América do Sul tem sido um hotspot global de expansão e intensificação agrícola, provocando grandes perdas em termos de biodiversidade e dos serviços ecossistêmicos não renováveis (PIQUER-RODRÍGUEZ et al., 2018). O ecoturismo pode ser uma estratégia de diversificação da economia e para conter a degradação ambiental na região.

O objetivo deste trabalho é propor roteiros integrados para o turismo de observação de aves na fronteira entre Brasil e Paraguai como estratégia de conservação da biodiversidade, dinamização econômica com base no ecoturismo, inclusão social e valorização cultural das comunidades localizadas no território de influência do Corredor Bioceânico.

\section{MATERIAL E MÉTODOS}

\section{1 Área de estudo}

O estudo foi realizado em Porto Murtinho (Brasil), Carmelo Peralta, a leste do departamento de Alto Paraguay, Concepción, Boquerón e Presidente Hayes (Paraguai). A sazonalidade climática é marcada mais pela variação de precipitação do que pela temperatura. Durante o ano, em função das inundações do Rio Paraguai, há um período bem definido de seca e cheia 
que condicionam o modo de vida de todas as comunidades biológicas, às quais se inclui a população humana.

O Chaco é um bioma subtropical árido localizado no centro da América do Sul, o segundo maior em extensão territorial superado, portanto, pela Amazônia. A formação savana estépica, ligada à província florística do Chaco, compreende $520.000 \mathrm{~km}^{2}$ (46\%) na Argentina, 230.000 $\mathrm{km}^{2}$ (32\%) no Paraguai, $90.000 \mathrm{~km}^{2}$ (15\%) na Bolívia e $9.000 \mathrm{~km}^{2}$ (7\%) no Brasil (PRADO, 1993). Existe uma predominância de vegetação xenomórfica, como plantas espinescentes, caducifólias, com folhas miúdas, cactos e bromélias (POTT et al., 2011).

No extremo leste do Chaco o ritmo das águas influencia os processos naturais e modificam a paisagem, tornando os ambientes sujeitos a alagamentos periódicos, condição que caracteriza o Chaco úmido na porção sul do Pantanal (PRADO et al., 1992; SILVA et al., 2008). Nessa faixa de transição entre Chaco úmido (Pantanal), Cerrado e florestas estacionais, as fitofisionomias se interpenetram e tornam os limites vegetacionais pouco visíveis. Há uma alta densidade da palmeira "carandá" (Copernicia alba), e outras espécies típicas como o "paratudo" (Handroanthus aureus) e a "piúva" (H. heptaphylla) (PRADO, 1993; POTT et al., 2011).

O município de Porto Murtinho faz fronteira com o Paraguai através do Rio Paraguai e do Rio Apa e, além das riquezas e belezas naturais, guarda elementos histórico-culturais muito significativos. Constituiu, por exemplo, cenário da Guerra da Tríplice Aliança no século XIX, (18641870) considerado o maior conflito armado internacional na América do Sul.

Neste estudo foram acessadas, em ambos os países, as fitofisionomias chaquenhas (POTT, 1997): savana estépica florestada (mata chaquenha), savana estépica arborizada (Chaco, cuja característica se assemelha à mata chaquenha, porém mais aberta e com indivíduos arbóreos de menor porte), savana estépica parque (carandazal) e savana estépica gramíneo-lenhosa (campo limpo nativo, campo sujo ou matorral e campo inundável). Outras unidades de paisagem, além dos chaquenhos, também foram analisadas, a saber: mata ripária, brejo, corixo, rio, baía ou lagoa, campo cerrado, Cerrado típico, florestas estacionais, áreas urbanas e áreas rurais com pastagens exóticas. A figura 1 apresenta a localização da área de estudo. 
Figura 1 - Área de estudo. Adaptado de Ecorregiões do Chaco

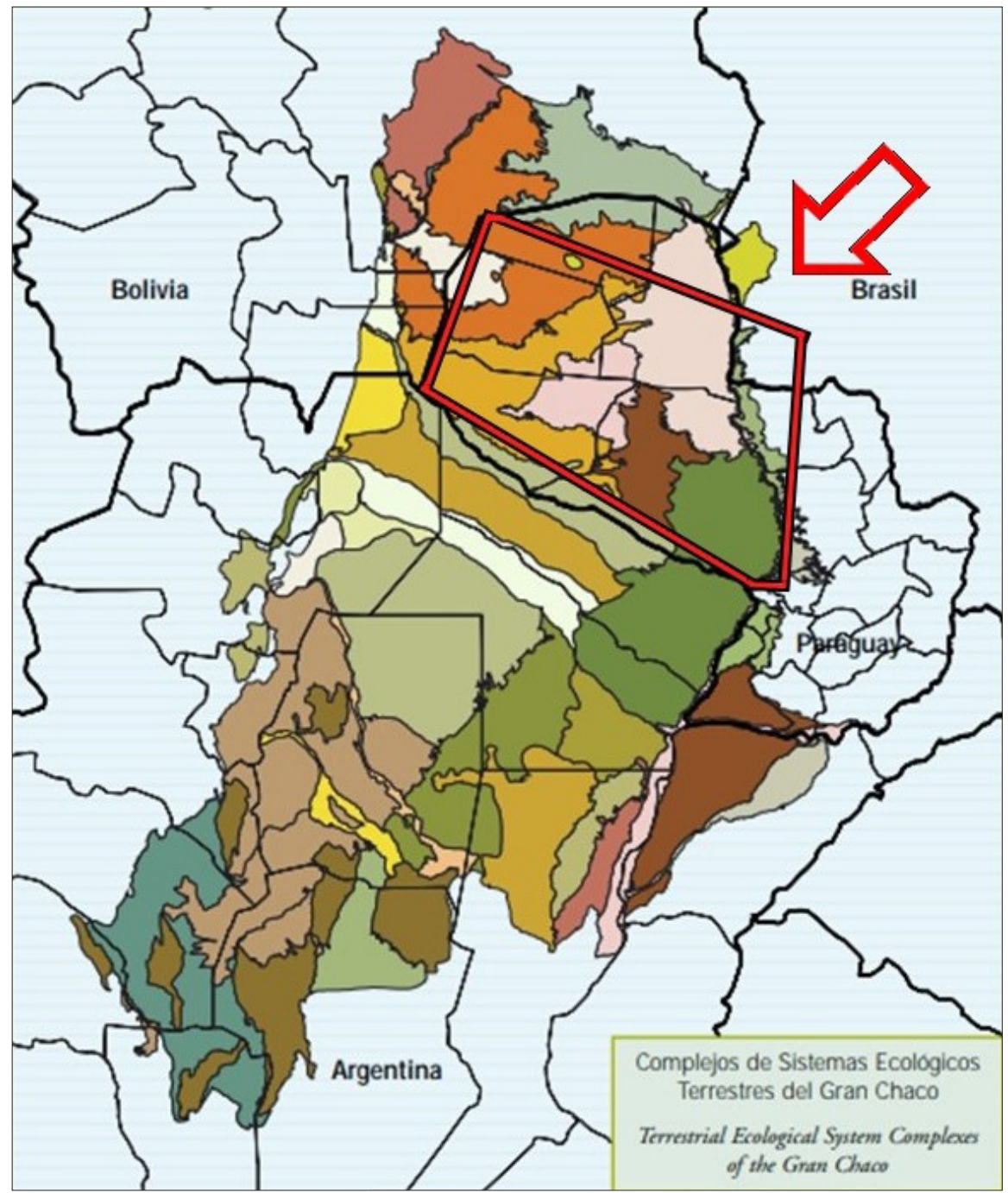

Fonte: TNC et al. (2005).

\subsection{Métodos}

Expedições pontuais e intensivas, porém, não sistematizadas foram realizadas no período entre 2002 e 2018, a fim de inventariar qualitativamente a avifauna da região. As expedições ou campanhas de campo foram empreendidas com duração variável de dias e horas de esforço amostral. Em geral, foram percorridos roteiros terrestres, lacustres e fluviais, com início às $06 \mathrm{~h}$ da manhã até às $11 \mathrm{~h}$ e, de $14 \mathrm{~h}$ às $17 \mathrm{~h} 30$ no período vespertino. Buscas noturnas iniciaram às $19 \mathrm{~h}$ até às $22 \mathrm{~h}$. Registros ocasionais e oportunísticos também foram considerados durante os deslocamentos. Os registros consistiram de observação visual direta das aves e/ou de sua vocalização. Sempre que possível, as aves foram fotografadas e as manifestações sonoras gravadas a fim de servirem de provas documentais. 


\section{RESULTADOS E DISCUSSÃO}

\section{1 Áreas potenciais para a observação de aves na região do Chaco entre Brasil e Paraguai}

A alta riqueza de aves no Chaco o consagra como destino promissor para o turismo de observação de aves e isto está diretamente relacionado à diversidade de hábitats existentes. Neste trabalho foram identificados 10 potenciais roteiros, dos quais, cinco encontram-se em Porto Murtinho (Brasil), dois binacionais (Brasil/Paraguai) e outros três no Paraguai. A conexão entre essas áreas consolida um importante roteiro binacional para o turismo de observação de aves no Chaco. A seguir, breve descrição de cada roteiro.

\subsubsection{Roteiro Parque Natural Municipal da Cachoeira do Apa - Porto Murtinho, Brasil}

O Parque Natural Municipal Cachoeira do Rio Apa está localizado às margens dos rios Perdido e Apa, na linha de fronteira imediata com o Paraguai. O Rio Apa é o último tributário do Rio Paraguai no Brasil. O Parque consiste de unidade de conservação de proteção integral e contempla unidades de paisagem como mata de galeria, mata estacional e os Rios Perdido e Apa. Com uma área de 58 hectares, está distante aproximadamente $85 \mathrm{~km}$ da área urbana de Porto Murtinho. Trata-se de uma área bastante propícia à prática do ecoturismo, sobretudo atividades de trilhas interpretativas, passeio fluvial e observação de vida selvagem, com destaque ao turismo de observação de aves. Possui alguma infraestrutura para atender visitantes, mas precisa ser aprimorado com centro de visitantes, serviços e outros equipamentos básicos. O Parque está na vizinhança da Comunidade Colônia Cachoeira do Apa que, embora possua alguns empreendidos e ofereça serviços turísticos, são direcionados ao turismo de pesca. É possível, contudo, adequar a estrutura existente para atender também ao ecoturismo.

\subsubsection{Roteiro Sede de Porto Murtinho, Brasil - Carmelo Peralta/Isla Margarita, Paraguai}

Este roteiro envolve a área urbana de Porto Murtinho, à margem esquerda do Rio Paraguai. Apesar da antropização decorrente da dinâmica urbana, ainda há remanescentes com espécies vegetais nativas e vários segmentos do rio com vegetação ciliar conservada. É comum a presença de algarrobos (Prosopis spp.), aromitas (Acacia spp.), olho de boi (Zizyphus oblongifolius), carandá (C. alba), alguns indivíduos de quebracho-vermelho (Schinopsis balansae) e de quebracho-branco (Aspidosperma quebracho-blanco), além de espécies vegetais introduzidas que compõem a arborização urbana. A cidade é contornada por um dique de contenção das cheias do Rio Paraguai, o qual delimita a área urbana do município.

Vegetação semelhante possui Carmelo Peralta no Paraguai, município do departamento de Alto Paraguai. Isla Margarita, localizada à margem direita do Rio Paraguai, integra o município de Carmelo Peralta e ambos apresentam uma diversidade de aves aquáticas, muitas delas migratórias. Para se chegar à Ilha, partindo de Porto Murtinho, basta atravessar o Rio Paraguai. Parte do roteiro pode ser feito embarcado com percursos ao longo do Rio Paraguai e corixos, e parte em área terrestre por vias urbanas da cidade de Porto Murtinho, Carmelo Peralta e Isla Margarita. 


\subsubsection{Roteiro Barranco Branco - Porto Murtinho, Brasil}

A região de Barranco Branco é caracterizada predominantemente pela presença da palmeira carandá, ao longo da margem esquerda do Rio Paraguai. As áreas internas apresentam campos alagáveis, além de extensas áreas com formações florestais chaquenhas. $\mathrm{O}$ acesso pode ser feito tanto por via fluvial (Rio Paraguai) como por via terrestre, este apenas no período seco.

\subsubsection{Roteiro Ingazeira - Porto Murtinho, Brasil / San Lázaro - Puerto Vallemí, Paraguai}

A região da Ingazeira localizada às margens do Rio Apa em Porto Murtinho, apresenta vegetação ciliar, mata chaquenha, carandás (Copernicia alba), baías e campos. A estrada que dá acesso ao local apresenta um mosaico dessas formações incluindo campos de pastagem exótica. Todo o percurso é propício à observação de aves, dada a variedade de ambientes presentes. 0 acesso é pode ser feito por via terrestre com distância de $60 \mathrm{~km}$ da sede de Porto Murtinho. Também é possível acessar por via fluvial, através do Rio Paraguai, partindo da sede de Porto Murtinho e chegando à Ingazeira pela foz do Rio Apa. A travessia do Rio Apa na região da Ingazeira dá acesso ao município de San Lázaro e Puerto Vallemí, departamento de Concepción, Paraguai. Essas localidades possuem alto potencial para observação de aves e contemplam áreas naturais relevantes para a prática do ecoturismo.

\subsubsection{Roteiro Dique e área rural adjacente}

A área rural nas imediações do dique de Porto Murtinho é caracterizada principalmente por campos de vegetação arbustiva xerófila e carandazal, restando poucas amostras de matas chaquenhas. A área está sujeita às inundações sazonais do Rio Paraguai que favorecem a manutenção de baías e campos alagáveis com taboais ou juncais e plantas aquáticas associadas. Além do carandá, é comum a ocorrência de espécies vegetais como barrigudas, olho de boi, aromitas e outras plantas espinescentes e de folhas pequenas. É comum também a presença da palmeira bocaiúva (Acrocomia sp.) que dá suporte ao ninho de vários psitacídeos, dentre os quais, a arara-azul e a arara-vermelha.

\subsubsection{Roteiro Estrada BR-267}

Convenciona-se denominar estrada a principal rodovia que dá acesso à cidade, BR-267, compreendendo, para este estudo, um trecho de $80 \mathrm{~km}$ antes chegar à sede de Porto Murtinho. É possível avistar várias unidades de paisagem, desde fitofisionomias de Cerrado, alguns remanescentes de floresta estacional em encosta de morros e áreas de transição entre ambientes terrestres e alagáveis. Ao se aproximar da cidade, nos últimos $10 \mathrm{~km}$, é possível notar a ocorrência de várias fitofisionomias do Chaco, de forma mais evidente e inconfundível.

\subsubsection{Roteiro Chaco Central - Paraguai}

Este roteiro inclui as salinas do Chaco Central do Paraguai que se formam ao longo do Riacho Yacaré Sur. Essas lagoas foram reconhecidas como Áreas Importantes para a Conservação das Aves - IBAS (BIRDLIFE INTERNATIONAL, s.d.), por concentrarem significativa diversidade de aves aquáticas, incluindo várias espécies praieiras migratórias, como o quase ameaçado de 
extinção, maçarico-acanelado (Calidris subruficollis). As lagoas são rodeadas de áreas de campo aberto (campo sazonalmente inundável) e de remanescentes florestais, onde ocorrem aves típicas de campos xerófitos (matorrales), incluindo 15 espécies endêmicas do Chaco (BIRDLIFE INTERNATIONAL, s.d.). O roteiro inclui várias reservas privadas, como Chaco Lodge e Estancia Campo María, Laguna Capitán, Selva Serena, Flor del Chaco, entre outras.

\subsubsection{Roteiro Chaco Úmido - Paraguai}

O roteiro inclui os locais próximos à capital Assunção: Chaco'i, Estancia La Rafaela e Estancia La Playada. A apenas 40 km de Assunção, esses locais apresentam alta riqueza de aves, tendo em vista o mosaico de ambientes disponíveis. As zonas úmidas nas áreas mais baixas permanecem inundadas pelas cheias do Rio Paraguai. As ilhotas de florestas e palmeirais com Copernicia alba (carandazais) formam outros ecossistemas no mosaico.

\subsubsection{Roteiro Reserva da Biosfera do Chaco - Paraguai}

Este roteiro inclui as maiores áreas protegidas do Paraguai, o Parque Nacional Defensores del Chaco e o Parque Nacional Médanos del Chaco. Essas duas áreas, juntamente com o Parque Nacional Teniente Enciso, formam um importante núcleo de conservação, com mais de um miIhão de hectares, na Reserva da Biosfera do Chaco, Paraguai. O ambiente é predominantemente composto de florestas xerofíticas com um denso e baixo dossel, característico do Chaco seco, com cactos e bromélias abundantes. Florestas higrófilas se formam em áreas baixas ou planícies aluviais e canais intermitentes, estes conhecidos por corixos.

O quadro 1 sintetiza algumas informações dos roteiros acima descritos e elenca espécies representativas para o turismo de observação de aves.

Quadro 1 - Áreas potenciais para o turismo de observação de aves na região do Chaco brasileiro e paraguaio, e respectivas aves representativas (Top 5) nas zonas de influência da Rota Bioceânica

\begin{tabular}{|c|c|c|c|}
\hline Roteiros & Localização & Espécies Top 5 & $\begin{array}{c}\text { Coordenadas } \\
\text { geográficas }\end{array}$ \\
\hline $\begin{array}{l}\text { 1. Parque Natural } \\
\text { Municipal da } \\
\text { Cachoeira do Apa e } \\
\text { entorno }\end{array}$ & $\begin{array}{l}\text { Porto Murtinho, } \\
\text { MS, Brasil }\end{array}$ & $\begin{array}{l}\text { águia-pescadora (Pandion haliaetus), } \\
\text { udu-de-coroa-azul (Momotus momota), } \\
\text { tiriba-fogo (Pyrrhura devillei), tiriba } \\
\text { (Pyrrhura frontalis), falcão-de-peito-laranja } \\
\text { (Falco deiroleucus) }\end{array}$ & $\begin{array}{l}22^{\circ} 10^{\prime} 21.08^{\prime \prime S} \\
57^{\circ} 30^{\prime} 58.5^{\prime \prime} \mathrm{W}\end{array}$ \\
\hline $\begin{array}{l}\text { 2. Área urbana de } \\
\text { Porto Murtinho }\end{array}$ & $\begin{array}{l}\text { Porto Murtinho, } \\
\text { MS, Brasil }\end{array}$ & $\begin{array}{l}\text { jacurutu (Bubo virginianus), arara-vermelha } \\
\text { (Ara chloropterus), pica-pau-de-barriga-preta } \\
\text { (Campephilus leucopogon) } \\
\text { pica-pau-de-testa-branca (Melanerpes } \\
\text { cactorum) e periquito-de-cabeça-preta } \\
\text { (Aratinga nenday) }\end{array}$ & $\begin{array}{l}21^{\circ} 41^{\prime} 42.01^{\prime \prime S} \\
57^{\circ} 52^{\prime} 42.2^{\prime \prime} \mathrm{W}\end{array}$ \\
\hline $\begin{array}{l}\text { 3. Porto Murtinho- } \\
\text { BR, Carmelo Peralta } \\
\text { e Isla Margarita-PY }\end{array}$ & $\begin{array}{l}\text { Porto Murtinho, } \\
\text { MS, Brasil }\end{array}$ & $\begin{array}{l}\text { carretão (Agelasticus cyanopus), garibaldi } \\
\text { (Chrysomus ruficapillus), anu-coroca } \\
\text { (Crotophaga major), sanã-parda (Laterallus } \\
\text { melanophaius), talha-mar (Rynchops niger) }\end{array}$ & $\begin{array}{l}21^{\circ} 42^{\prime} 37.7^{\prime \prime} \mathrm{S} \\
57^{\circ} 54^{\prime} 8.7^{\prime \prime} \mathrm{W}\end{array}$ \\
\hline
\end{tabular}




\begin{tabular}{|c|c|c|c|}
\hline Roteiros & Localização & Espécies Top 5 & $\begin{array}{l}\text { Coordenadas } \\
\text { geográficas }\end{array}$ \\
\hline 4. Barranco Branco & $\begin{array}{l}\text { Porto Murtinho, } \\
\text { MS, Brasil }\end{array}$ & $\begin{array}{l}\text { rapazinho-do-chaco (Nystalus striatipectus), } \\
\text { sanhaçu-de-fogo (Piranga flava), } \\
\text { suindara (Tyto furcata), choca-da-mata } \\
\text { (Thamnophilus caerulescens, tiriba-fogo } \\
\text { (Pyrrhura devillei) }\end{array}$ & $\begin{array}{l}21^{\circ} 5^{\prime} 58.6^{\prime \prime S} \\
57^{\circ} 50^{\prime} 37.8^{\prime \prime} \mathrm{W}\end{array}$ \\
\hline $\begin{array}{l}\text { 5. Ingazeira- San } \\
\text { Lázaro-Vallemí }\end{array}$ & $\begin{array}{l}\text { Porto Murtinho, } \\
\text { MS, Brasil e San } \\
\text { Lazaro/Vallemi, } \\
\text { Paraguai }\end{array}$ & $\begin{array}{l}\text { águia-cinzenta (Urubitinga coronata), } \\
\text { caboclinho-de-barriga-vermelha (Sporophila } \\
\text { hypoxantha), azulão (Cyanoloxia brissonii), } \\
\text { papa-moscas-canela (Polystictus pectoralis), } \\
\text { cochicho (Anumbius annumbi) }\end{array}$ & $\begin{array}{l}22^{\circ} 4^{\prime} 53.6^{\prime \prime S} \\
57^{\circ} 56^{\prime} 23.1^{\prime \prime} \mathrm{W}\end{array}$ \\
\hline $\begin{array}{l}\text { 6. Dique de Porto } \\
\text { Murtinho e área } \\
\text { rural adjacente }\end{array}$ & $\begin{array}{l}\text { Porto Murtinho, } \\
\text { MS, Brasil }\end{array}$ & $\begin{array}{l}\text { japuíra (Cacicus chrysopterus), } \\
\text { alegrinho-do-chaco (Inezia inornata), } \\
\text { pica-pau-chorão (Veniliornis mixtus), } \\
\text { capacetinho (Microspingus melanoleucus), } \\
\text { saracuruçu (Aramides ypecaha) }\end{array}$ & $\begin{array}{l}21^{\circ} 41^{\prime} 18.1^{\prime \prime S} \\
57^{\circ} 52^{\prime} 46.8^{\prime \prime} \mathrm{W}\end{array}$ \\
\hline $\begin{array}{l}\text { 7. Estrada BR- } 267 \text { e } \\
\text { adjacências }\end{array}$ & $\begin{array}{l}\text { Porto Murtinho, } \\
\text { MS, Brasil }\end{array}$ & $\begin{array}{l}\text { arara-azul (Anodorhynchus hyacinthinus), } \\
\text { arara-vermelha (Ara chloropterus), cardeal- } \\
\text { do-banhado (Amblyramphus holosericeus), } \\
\text { viuvinha-de-óculos (Hymenops } \\
\text { perspicillatus), tuiuiú (Jabiru mycteria) }\end{array}$ & $\begin{array}{l}21^{\circ} 41^{\prime} 59.33^{\prime \prime S} \\
57^{\circ} 51^{\prime} 47.38^{\prime \prime} \mathrm{W}\end{array}$ \\
\hline $\begin{array}{l}\text { 8. Chaco Central- } \\
\text { Paraguai }\end{array}$ & $\begin{array}{l}\text { Presidente Hayes } \\
\text { y Boquerón, } \\
\text { Paraguay }\end{array}$ & $\begin{array}{l}\text { águia-cinzenta (Urubitinga coronata), } \\
\text { coruja-do-chaco (Strix chacoensis), } \\
\text { flamingo-chileno (Phoenicopterus } \\
\text { chilensis), pica-pau-preto (Dryocopus } \\
\text { schulzi), seriema-de-perna-preta (Chunga } \\
\text { burmesteiri) }\end{array}$ & $\begin{array}{l}22^{\circ} 33^{\prime} 0^{\prime \prime} \mathrm{S} \\
59^{\circ} 22^{\prime} 59^{\prime \prime} \mathrm{W}\end{array}$ \\
\hline $\begin{array}{l}\text { 9. Chaco Úmido- } \\
\text { Paraguai }\end{array}$ & Presidente Hayes & $\begin{array}{l}\text { tesoura-do-campo (Alectrurus risora), } \\
\text { caboclinho-de-papo-escuro (Sporophila } \\
\text { ruficollis), tricolino-pardo (Pseudocolopteryx } \\
\text { dinelliana), papa-moscas-canela (Polystictus } \\
\text { pectoralis) }\end{array}$ & $\begin{array}{l}24^{\circ} 59^{\prime} 50^{\prime \prime S} \\
57^{\circ} 27^{\prime} 00^{\prime \prime} \mathrm{W}\end{array}$ \\
\hline $\begin{array}{l}\text { 10. Reserva da } \\
\text { Biosfera do Chaco }\end{array}$ & $\begin{array}{l}\text { Boquerón y } \\
\text { Alto Paraguay, } \\
\text { Paraguay }\end{array}$ & $\begin{array}{l}\text { inambu-do-chaco (Nothoprocta } \\
\text { cinerascens), martineta-do-chaco (Eudromia } \\
\text { formosa), falcãozinho-cinza (Spiziapteryx } \\
\text { circumcincta), canário-de-crista-preta } \\
\text { (Lophospingus pusillus), } \\
\text { tico-tico-de-coroa-castanha (Rhynchospiza } \\
\text { strigiceps) }\end{array}$ & $\begin{array}{l}20^{\circ} 13^{\prime} 0^{\prime \prime S} \\
60^{\circ} 12^{\prime} 0^{\prime \prime} W\end{array}$ \\
\hline
\end{tabular}

Com registros de aproximadamente 350 espécies no Chaco brasileiro (BENITES et al., 2017), no Paraguai 422 espécies em Chaco Seco e 392 no Chaco Úmido (Guyra Paraguay, 2004), a riqueza de aves e o potencial para o turismo de observação de aves na região são incontestáveis.

\subsection{Espécies em destaque}

Batuqueiro-chaquenho (Saltatricula multicolor): recentemente encontrado em Porto Murtinho, cujo registro fotográfico está arquivado no banco de imagens da plataforma de ciência cidadã WikiAves (SILOTTI, 2015). É uma espécie considerada endêmica ao Chaco, onde é comum nos ambientes xerófilos (SHORT, 1975; CRACRAFT, 1985; DELHEY; SCOROLLI, 2002). 
Rapazinho-do-chaco (Nystalus striatipectus): espécie desmembrada de N. maculatus (rapazinho-dos-velhos), ocorre no Chaco e Pantanal (SIGRIST, 2013). Embora comum no Mato Grosso do Sul, muitos observadores apreciam o encontro com essa espécie em função de sua distribuição geográfica restrita.

Tesoura-do-campo (Alectrurus risora): considerada espécie meridional campestre pouco conhecida (SICK, 1997), é endêmica da província dos Pampas, rara e mundialmente ameaçada de extinção (IUCN, s.d.). Há afinidade vegetacional e de avifauna entre as áreas campestres do Chaco e dos Pampas (STRAUBE; DI GIACOMO, 2007). A perda de habitat por substituição das áreas de campo nativo por pastagens exóticas e plantações agrícolas são as principais ameaças a essa espécie.

Tiriba-fogo (Pyrrhura devillei): com distribuição restrita ao oeste de Mato Grosso do Sul, é encontrada no Chaco paraguaio e boliviano (SIGRIST, 2013). Atrativa aos observadores de aves por sua raridade no país.

Algumas espécies sem registros para o Brasil (PIACENTINI et al., 2015), podem ser encontradas com frequência no Paraguai, próximo à fronteira, tais como: coruja-do-chaco (Strix chacoensis), falcãozinho-cinza (Spiziapteryx circumcincta) e outras. Com base na localização dos registros no Paraguai não seria impossível encontrá-las também no Brasil. O estímulo ao turismo de observação de aves em Porto Murtinho pode ser uma oportunidade para que sejam encontradas essas e outras espécies que ainda carecem de registros para o Brasil.

\subsection{As espécies migratórias}

Várias espécies são migrantes na região e apresentam diferentes padrões migratórios e no uso dos ambientes. Os tiranídeos (bem-te-vis, suiriris e afins) migrantes (migrantes austrais) constituem o maior grupo de aves austrais migratórias e chegam, em sua maioria, no final da estação seca e início da chuvosa, permanecendo durante a extensão do período chuvoso que coincide com a abundância de alimento (insetos e frutos) e a reprodução (HAYNES; SCHARF; RIDGELY, 1994). Há os migrantes austrais do Norte e do Sul.

Os migrantes austrais do Norte são definidos como aqueles que se reproduzem nas zonas temperadas continentais da América do Sul e migram ao norte, em direção à Amazônia, durante o inverno austral (CHESSER, 1994; HAYNES; SCHARF; RIDGELY, 1994). Alguns exemplos de migrantes austrais são as guaracavas (Elaenia spp.), várias espécies de andorinhas, e os caboclinhos do grupo Sporophila, dentre os quais, caboclinho-de-papo-escuro (Sporophila ruficollis), bigodinho (S. lineola), caboclinho-de-barriga-vermelha (S. hypoxantha) e outros. Os migrantes austrais do Sul se reproduzem no Sul da América do Sul e se dirigem às latitudes mais tropicais, por exemplo, o Chaco, Cerrado e Pantanal, durante o inverno austral (HAYNES et al., 1994). Alguns exemplos são: príncipe (Pyrocephalus rubinus), viuvinha-de-óculos (Hymenops perspicillata), tricolino-oliváceo, amarelinho-do-junco e tricolino-pardo (Pseudocolopteryx acutipennis, P. flaviventris e $P$. dinelliana, respectivamente), sanhaçu-papa-laranja (Pipraeidea bonariensis) e canário-de-crista-preta (Lophospingus pusillus).

Já os Charadriiformes (maçaricos e afins) e outras originárias do Hemisfério Norte não se reproduzem no continente sul-americano, mas utilizam o território como áreas de invernada, fazendo paradas para a alimentação e, frequentemente, seguem até a Argentina, permanecendo em descanso reprodutivo, motivo pelo qual torna difícil, muitas vezes, a identificação morfológica 
por assumirem plumagem semelhante e inconspícua entre as espécies (SICK, 1997). Os mesmos retornam à América do Norte na primavera setentrional para reprodução. Os Charadriiformes são considerados biomonitores, uma vez que permanecem em áreas não poluídas de onde retiram seu alimento (SICK, 1997). Em resumo, o Chaco representa importante rota de migração de aves na América do Sul.

\subsection{O birdwatching e a relevância de roteiros integrados}

O birdwatching pode representar um caminho viável para o desenvolvimento do ecoturismo. No entanto, precisa avançar no sentido de planejar, preparar, amadurecer e profissionalizar os atores envolvidos e interessados em negócios ecoturísticos na região. O público potencial dessa modalidade de turismo, conforme pesquisa realizada no Peru, encontra-se, basicamente, nas Américas e Europa e praticam um gasto médio diário de U\$178 nos lugares que visitam (PROMPERÚ, 2014). Há um expressivo impacto de ganhos em toda a cadeia, desde hospedagem, transporte, alimentos e bebidas, comercialização de equipamentos como câmeras, binóculos, vestuário, utensílios de campo e souvenires, além de todos os impostos sobre o rendimento e empregos relacionados à observação de aves (CHAMBER, 2014).

Há várias vantagens e benefícios socioculturais, econômicos e ambientais da observação de aves: estimula boas práticas no turismo, visto que o observador não deixa resíduos sólidos nos ambientes visitados e muitas vezes se compromete com causas socioambientais; não se extrai nada do ambiente, além de imagens fotográficas; é uma atividade relaxante; pode se tornar um estilo de vida para as populações locais, incorporando-se intrinsecamente à cultura e, no caso da fronteira, pode fortalecer a integração cultural entre os países; zela pela biodiversidade entendendo que ela é a principal matéria-prima para a vida em toda a sua plenitude.

As relações humanas contêm em si significados de pluralidade, transcendência, criticidade, consequência e temporalidade, haja vista que o ser humano não apenas está no mundo, mas com o mundo, no sentido de criação, recriação e decisão, aplicando-se movimento e dinamização (FREIRE, 2005). Nesta concepção, admite-se que o ser humano não está isolado no mundo, mas interage com outros seres humanos e com seres não humanos igualmente importantes. Daí a preocupação com um tipo de desenvolvimento que não seja reducionista, hegemônico e excludente. É preciso enfrentar o desafio de não cair na simplificação do conceito de desenvolvimento e criar possibilidades locais a partir das potencialidades existentes.

As áreas de fronteira devem ser reconhecidas como espaços de singularidade e podem catalisar processos de desenvolvimento e de integração territorial e regional (FRANÇA; PIRANI, 2013). Entre as peculiaridades na faixa de fronteira entre Brasil e Paraguai, nos limites de Mato Grosso do Sul, estão as questões ambientais e as relações sociais que devem ser respeitadas e reconhecidas como oportunidades para o desenvolvimento sustentável. Essa faixa de fronteira rica em biodiversidade encontra-se no centro da Corredor Bioceânico e tem alto potencial para diversas práticas sustentáveis, entre elas o ecoturismo e o turismo de observação de aves.

O interesse deste trabalho foi mostrar não apenas a presença de aves e sua riqueza, mas o valor da mesma e como isso se apresenta também como uma das expressões da cultura local. Sem dúvida, a biodiversidade se mostra como um ativo de desenvolvimento importante nas diversas perspectivas, neste caso, turística e ambiental, e mais, integrada ao país fronteiriço, Paraguai. O potencial para o ecoturismo é comum aos dois países e os elementos naturais não reconhecem 
fronteiras políticas. Portanto, é preciso análise integrada sobre a valoração da biodiversidade em projetos de grande infraestrutura, e que se avalie, de forma efetiva e imparcial, todos os aspectos que compõem essa totalidade: elementos naturais, sociais e econômicos.

Nesse caminho pelo progresso e desenvolvimento local, o turismo de observação de aves e de vida selvagem no Chaco se coloca como uma opção menos predatória e mais alinhada com a sustentabilidade dos territórios, embora menos hegemônica em comparação ao turismo de massa que povoa o ideal e o imaginário de expressiva parcela da sociedade. E, cabe ressaltar, que não se trata de resignação, mas de perspectiva viável com muitos exemplos exitosos Brasil afora.

A elaboração de roteiros integrados de birdwatching, Brasil e Paraguai, concorre para o incremento da atividade turística nos dois países, os quais têm apresentado números cada vez crescentes de adeptos da observação de aves, bem como abrirá possibilidades para atração de turistas especializados vindos de outros países.

Outro fator importante que deve ser considerado é a qualidade desse turismo. Turistas mais especializados exigem segurança e qualidade dos serviços adquiridos, o que demanda formatação de roteiros e produtos e preparação dos atores envolvidos. A comercialização de roteiros se torna imprescindível para a atração de um público com maior qualidade de consumo e consciência ambiental.

\subsection{O impacto de uma rota para escoamento da produção com travessia numa grande região natural e com fortes tradições culturais}

O projeto de integração sul-americano permite vislumbrar promissoras interligações entre o Brasil e os países da América do Sul que possuem saídas para o Pacífico, propiciando uma ligação com o continente asiático e, em especial, com a China (SILVA et al., 2011). No entanto, seria muito reducionista olhar somente sob esse prisma.

A degradação ambiental manifesta-se como um sintoma de uma crise civilizatória marcada pelo modelo de modernidade, em que o desenvolvimento da tecnologia predomina sobre a destruição da natureza, de modo que a questão ambiental problematiza as próprias bases da produção e aponta para a desconstrução do paradigma econômico da modernidade, bem como para a construção de futuros possíveis, baseados nos limites que estabelecem as leis da natureza, assim como nos potenciais culturais e da criatividade humana (LEFF, 2009).

Rasgar o Pantanal e o Chaco para transporte rodoviário da produção agropecuária parece moderno e prático na lógica do imediatismo, mas deve-se problematizar seus efeitos e mais, buscar formas econômicas locais para que a população não fique reduzida à subserviência nos serviços de logística portuária.

Leff (2009) afirma que o desenvolvimento sustentável vai além dos propósitos de capitalizar a natureza e de ecologizar a ordem econômica, mas passa antes pela socialização da natureza e o manejo comunitário dos recursos, baseados em princípios de diversidade biológica e cultural. Assim, segundo o autor, a democracia e a equidade redefinem-se no campo da sustentabilidade com base nas condições culturais e políticas de reapropriação do ambiente. Uma ressignificação dos bens naturais, suas formas de uso e sua apropriação passa certamente pelo reconhecimento da diversidade de vida selvagem existente nessa fronteira entre Brasil e Paraguai, que pode ser utilizada de forma sustentável, por exemplo, pelo ecoturismo e o turismo de observação de aves.

O crescimento econômico não deve ocorrer a qualquer custo, sendo preciso garantir um desenvolvimento sustentável coerente com perspectivas de longo prazo (FONSECA, 2015). Estudos, 
reflexões e debates sobre os caminhos viáveis para se estimular e alcançar o desenvolvimento sustentável têm sido pautas atuais em agendas nacionais e internacionais. Groot et al. (2010) consideram que em tempos atuais é amplamente reconhecido que a conservação da biodiversidade e estratégias de manejo não representam necessariamente um conflito entre natureza e desenvolvimento, mas que os investimentos em conservação, restauração e uso sustentável dos ecossistemas geram substanciais benefícios ecológicos, socioculturais e econômicos. O ecoturismo pode ser um exemplo do quanto assegurar a proteção e a estabilidade dos ecossistemas resultam em benefício pleno e extensivo a vários contextos.

O turismo de observação de aves integrado ao de observação de vida selvagem precisa ser reconhecido como elemento importante e inegável da matriz econômica e cultural de Porto Murtinho e da região do extremo leste da província do Chaco na América do Sul. A economia pode e deveria operar dentro das potencialidades naturais de cada território sem, contudo, ignorar formas de uso da terra já consolidadas. Mas, como integrar e gerar sinergia entre as distintas cadeias de produção são alguns dos desafios quando se busca uso sustentável dos bens naturais e preservação do patrimônio cultural e imaterial da região. Primeiro é necessário conhecer e inventariar as potencialidades, depois reconhecê-las e, por último, estruturar e aprimorar em um processo interdisciplinar.

\section{CONSIDERAÇÕES FINAIS}

Diversas são as perspectivas de desenvolvimento a partir de uma rota de ligação de grande extensão para comércio e transporte de produção como a prevista por essa transoceânica. No entanto, nem todas as comunidades existentes no percurso de uma rota deste porte se reconhece dentro do sistema. É preciso pensar em benefícios para a massa da população de forma distribuída e não segregada ou individualizada. Conhecer, reconhecer e respeitar as comunidades locais seus hábitos e hábitats, nos permitem vislumbrar modelos de produção que envolvam o protagonismo das comunidades, a valorização da sociobiodiversidade e a qualificação profissional dos atores envolvidos de forma a fomentar e a instigar o desenvolvimento sustentável a partir de produtos e práticas que gerem ganhos econômicos sem extrair ou exaurir elementos da natureza.

A integração entre Brasil e Paraguai é extremamente benéfica no sentido da união de esforços para potencializar a comercialização de roteiros de ecoturismo interna e externamente. Entretanto, a qualidade de serviços deve ser priorizada, deixando que as aves e a cultura local sejam o marco de encantamento e distinção entre os países.

Observar aves se constitui também de frugalidade, ou seja, desfrutar da satisfação de estar na natureza e com a natureza próxima. Para o bem da humanidade não é possível que a produção excessiva e a acumulação de capital ofusquem, sobreponham e superem a oportunidade da frugalidade e das amenidades proporcionadas pelo encantamento com mundo natural. A partir da observação de aves, é possível valorizar os serviços ecossistêmicos, conservar a biodiversidade e respeitar as comunidades locais. Assim, o ecoturismo precisa de apoio e incentivo para coexistir com outras formas de produção no Corredor Bioceânico.

\section{AGRADECIMENTOS}

Agradecemos ao Instituto Mamede de Pesquisa Ambiental e Ecoturismo, à Secretaria Municipal de Cultura e Turismo de Porto Murtinho, ao Exército Brasileiro, 2a Cia Fron pelo apoio 
logístico nas expedições em muitas etapas deste trabalho, ao Fábio Santos pelo apoio local, especialmente durante as expedições de 2008 e 2015 na região de fronteira. À Fundação de Turismo do Mato Grosso do Sul (FUNDTUR), à World Wildlife Fund Paraguay e à Oficina Ejecutiva de la Red Hemisférica de Reservas para Aves Playeras - Paraguay pela parceria.

\section{REFERÊNCIAS}

BAUMANN, Matthias; ISRAEL, Christoph; PIQUER-RODRÍGUEZ, Maria; GAVIER-PIZARRO, Gregorio Ignacio. Deforestation and cattle expansion in the Paraguayan Chaco 1987-2012. Regional Environmental Change, Dordrecht, v. 17, n. 4, p. 1179-91, 2017.

BENITES, Maristela; MAMEDE, Simone; CARVALHO, Guto; ALHO, Cleber JR. Assessment of avian occurrence in the Brazilian chaco. Avian \& Wildlife Biology, Oklahoma, v. 2, n. 4, p. 99-113, 2017.

BIRDLIFE INTERNATIONAL. Important Bird Areas fact sheet: Lagunas Saladas - Riacho Yacaré. [S.d.]. Disponível em: http://www.birdlife.org. Acesso em: 1ㅇfev. 2019.

CHAMBER, Bradnee. 60 Million american birdwatchers chase ever-shrinking quarry. Live Science, New York, 2014. Disponível em: https://www.livescience.com/45514-bird-numbers-plummet-but-birdwatchingpopular.html. Acesso em: 20 jan. 2019.

CHESSER, Terri. R. Migration in South America: an overview of the Austral system. Bird Conservation International, Cambridge, v. 4, n. 2-3, p. 91-107, 1994.

COLE, James S.; SCOTT, David. Segmenting participation in wildlife watching: A comparison of casual wildlife watchers and serious birders. Human Dimensions of Wildlife, Fort Collins, v. 4, n. 4, p. 44-61, 1999.

COOPER, Caren B.; SMITH, Jennifer A. Gender patterns in bird-related recreation in the USA and UK. Ecology and Society, Wolfville, v. 15, n. 4, p. 1-13, 2010.

CRACRAFT, Joel. Biological diversification and its causes. Annals of the Missouri Botanical Garden, Missouri, v. 72, n. 4, p. 794-822, 1985.

DELHEY, Kaspar V.; SCOROLLI, Alberto L. Abundancia relativa y estatus de residencia del pepitero chico (Saltatricula multicolor) en el sudoeste de la provincia de Buenos Aires, Argentina. El Hornero, Buenos Aires, v. 17, n. 1, p. 41-4, 2002.

FONSECA, Rafael O. Compensação ambiental: da contradição à valoração do meio ambiente no Brasil. Sociedade \& Natureza, Uberlândia, v. 27, n. 2, 2015.

FRANÇA, Maristela O.; PIRANI, Rodrigo, M. M. Políticas e instrumentos de desenvolvimento territorial em ambiente de fronteira- reflexões e aprendizados. Interações, Campo Grande, v. 14, n. especial, p. 37-48, 2013.

FREIRE, P. Educação como prática da liberdade. 18. ed. São Paulo: Paz e Terra, 2005.

GROOT, RudolfS.; ALKEMADE, Rob; BRAAT, Leon; HEIN, Lars G.; WILLEMEN, Louise. Challenges in integrating the concept of ecosystem services and values in landscape planning, management and decision making. Ecological Complexity, Leicester, v. 7, n. 3, p. 260-72, 2010.

GUYRA PARA GUAY. Lista comentada de las aves de Paraguay. Asunción: Guyra Paraguay, 2004.

HAYES, Floyd E.; SCHARF, Paul A.; RIDGELY, Robert S. Austral Bird Migrants in Paraguay. The Condor, Washington, v. 96, n. 1, p. 83-97, 1994. 
INTERNATIONAL UNION FOR CONSERVATION OF NATURE'S (IUCN). The IUCN Red List of threatened species. Alectrurus risora. [S.d]. Disponível em: https://www.iucnredlist.org/species/22700303/93768087. Acesso em: 27 jan. 2019.

KJOLSROD, Lise. You can really start birdwatching in your backyard, and from there the sky's the limit. In: KJOLSROD, Lise (Ed.). Leisure as source of knowledge, social resilience and public commitment. Leisure Studies in a Global Era. London: Palgrave Macmillan, 2019.

LEFF, Enrique. Ecologia, capital e cultura: a territorialização da racionalidade ambiental. Petrópolis: Vozes, 2009.

MAMEDE, Simone; MATA, Paola Santos; BENITES, Maristela; SENDODA, Andrea M.; PLUMEY, Bruno. Expedição científica biofronteira do Pantanal: diagnóstico para proposições de manejo à mastofauna na fronteira do Brasil com o Paraguai. In: CONGRESSO BRASILEIRO DE MASTOZOOLOGIA, 4., 11-22 ago. 2008, São Lourenço, MG. Resumos eletrônicos [...]. São Lourenço: UFMG, 2008. Disponível em: http:// sbmz.org/wp-content/uploads/2017/09/Livro-de-Resumos-CBMz-2008red.pdf. Acesso em: 20 jan. 2019.

PIACENTINI, Vitor Q. et al. Annotated checklist of the birds of Brazil by the Brazilian Ornithological Records Committee/Lista comentada das aves do Brasil pelo Comitê Brasileiro de Registros Ornitológicos. Revista Brasileira de Ornitologia. Revista Brasileira de Ornitologia, Rio Grande, v. 23, n. 2, p. 90-298, 2015.

PIQUER-RODRÍGUEZ, María; BUTSIC, Van; GÄRTNER, Philipp; MACCHI, L.;. BAUMANN, M; GAVIER PIZARRO, G.; VOLANTE, J. N.; GASPARRI, I. N. M.; KUEMMER, T. Drivers of agricultural land-use change in the Argentine Pampas and Chaco regions. Applied geography, Kennesaw, v. 91, p. 111-22, 2018.

POTT, Arnildo. Vegetação. Plano de Conservação da Bacia do Alto Paraguai (PCBAP). Diagnóstico dos meios físico e biótico: meio biótico. v. 2, tomo 3. Brasília: Ministério do Meio Ambiente, 1997.

POTT, Arnildo; OLIVEIRA, Ademir K. M.; DAMASCENO-JÚNIOR, Geraldo A; SILVA, J. S. V. Plant diversity of the Pantanal wetland. Brazilian Journal of Biology, São Carlos, v. 71, n. 1, p. 265-73, 2011.

PRADO, Darién E. What is the Gran Chaco vegetation in South America? A review. Contribution to the study of flora and vegetation of the Chaco V. Candollea, Genebra, v. 48, p. 145-72, 1993.

PRADO, Darién E.; GIBBS, Peter E.; POTT, Arnildo; POTT, Vali J. The Chaco-Pantanal transition in southern Mato Grosso, Brazil. In: FURLEY, Peter A; PROCTOR, John; RATTER, John A. (Ed.). Nature and dynamics of forest-savanna boundaries. 5. ed. London: Chapman \& Hall, 1992.

PROMPERÚ. Perfil del Observador de aves: el turismo en cifras- 2013. Lima: Comisión de la Promoción del Perú para la Exportación y el Turismo (PromPerú), 2014.

RIBEIRO, Mara. A. A espetacularização da natureza no Pantanal. Interações, Campo Grande, MS, v. 19, n. 4, p. 803-12, out./dez. 2018.

SHORT, Lester L. A zoogeographic analysis of the South American Chaco avifauna. Bulletin of the AMNH, New York, v. 154, n. 3, p. 163-352, 1975.

SICK, Helmut. Ornitologia Brasileira. Rio de Janeiro: Nova Fronteira, 1997.

SIGRIST, Tomas. Guia de campo Avis Brasilis - Avifauna Brasileira. São Paulo: Avis Brasilis, 2013.

SILOTTI, Regis. V. Saltatricula multicolor (Burmeister, 1860), 2015. WA1903214. WikiAves- A Enciclopédia das Aves do Brasil. Disponível em: http://www.wikiaves.com/1903214. Acesso em: 2 abr. 2017. 
SILVA, João V.; CAPUTO, Ana C. B. Localização e distribuição da vegetação Savana Estépica (Chaco) no Pantanal brasileiro. In: Simpósio de Geotecnologias no Pantanal, 3. 2010, Cáceres. Anais eletrônicos [...]. Cáceres: Embrapa Informática Agropecuária/INPE, 2010. p. 314-23. Disponível em: https://ainfo.cnptia. embrapa.br/digital/bitstream/item/23282/1/p226.pdf. Acesso em: 2 set. 2018.

SILVA, Marta P.; MAURO, Rodiney A.; ABDON, Myrian; et al. Estado de Conservação do Chaco (Savana Estépica) brasileiro. In: SIMPÓSIO NACIONAL CERRADO, 9., SIMPÓSIO INTERNACIONAL SAVANAS TROPICAIS, 2., Planaltina. Anais eletrônicos [...]. Brasília: Embrapa Cerrados, 2008. Disponível em: http:// simposio.cpac.embrapa.br/simposio\%20em\%20pc210\%20(Pc210)/trabalhos_pdf/00789_trab1_ap.pdf. Acesso em: 2 set. 2018.

SILVA, Roberto; KAWANO, Bruno; MORES, Giana; BLOIS, Henrique Dias. Exportação da soja brasileira: será o corredor bioceânico uma alternativa para o seu escoamento? Revista Teoria e Evidência Econômica, Passo Fundo, v. 17, n. 36, p. 126-42, 2011.

STRAUBE, Fernando C.; DI GIÁCOMO, Adrian. A avifauna das regiões subtropical e temperada do Neotrópico: desafios biogeográficos. Ciência \& Ambiente, Santa Maria, n. 35, p. 137-66, 2007.

STRAUBE, Fernando C.; URBEN-FILHO, Alberto; PIVATTO, Maria A. C.; NUNES, Alessandro Pacheco; TOMÁS, Walfrido Moraes. Nova contribuição à ornitologia do Chaco brasileiro (Mato Grosso do Sul, Brasil). Atualidades ornitológicas, v. 134, p. 1-27, 2006a.

STRAUBE, Fernando C.; URBEN-FILHO, Alberto; NUNES, Alessandro P.; TOMÁS, Walfrido Moraes; VIEIRADA-ROCHA, Maria Cecília. Avifauna do Pantanal de Nabileque (Mato Grosso do Sul, Brasil). Atualidades Ornitológicas, Ivaiporã, v. 134, p. 28-50, 2006b.

THE NATURE CONSERVANCY (TNC); Fundación Vida Silvestre Argentina (FVSA); Fundación para el Desarrollo Sustentable del Chaco (DeSdel Chaco); y Wildlife Conservation Society Bolivia (WCS). Evaluación Ecorregional del Gran Chaco Americano / Gran Chaco Americano Ecoregional Assessment. Buenos Aires: Fundación Vida Silvestre Argentina, 2005.

TUBELIS, Dárius P.; TOMAS, Walfrido M. Birds species of the Pantanal wetland, Brazil. Ararajuba, Rio Grande, v. 11, n. 1, p. 5-37, 2003.

U.S. FISH; WILDLIFE SERVICE. 2016 National survey of fishing, hunting, and wildlife-associated recreation. U.S. Department of the Interior, U.S. Fish and Wildlife Service, and U.S. Department of Commerce, U.S. Census Bureau. Disponível em: https://wsfrprograms.fws.gov/subpages/nationalsurvey/nat_survey2016. pdf. Acesso em: 2 set. 2018.

ZYSKOWSKI, Kristof.; ROBBINS, Mark. B.; PETERSON, Andrew; ZYSKOWSKI, Kimberly. Avifauna of the northern Paraguayan Chaco. Ornitología Neotropical, Buenos Aires, v. 14, p. 247-62, 2003.

\section{Sobre os autores:}

Simone Mamede - Doutora e mestre em Meio Ambiente e Desenvolvimento Regional pela Universidade para o Desenvolvimento do Estado e da Região do Pantanal (UNIDERP). Pesquisadora em biodiversidade, bióloga, educadora ambiental, graduada em gestão do turismo. Sócio-diretora do Instituto Mamede de Pesquisa Ambiental e Ecoturismo. E-mail: simone.mamede1@gmail.com, Orcid: http://orcid.org/0000-0002-7785-320X

Maristela Benites - Mestre em Ecologia e Conservação pela Universidade Federal de Mato Grosso do Sul (UFMS). Bióloga, pesquisadora em ornitofauna e em ecoturismo, educadora 
ambiental. Pesquisadora no Instituto Mamede de Pesquisa Ambiental e Ecoturismo. Acadêmica do curso de Geografia na Universidade Estadual de Mato Grosso do Sul (UEMS). E-mail: maris.benites@gmail.com, Orcid: http://orcid.org/0000-0003-0024-1122

Alberto Esquivel - PhD. em Ornitologia. Biólogo. Pesquisador em Ornitologia World Wildlife Fund - Paraguay, Pesquisa aves do Paraguai, em especial da Mata Atlântica e desenvolve projetos para ajudar a conservar a biodiversidade de seu país. E-mail: alberto.esquivel@wildlife.com.py, Orcid: http://orcid.org/0000-0003-0331-047X

Robert Clay - Ph.D. em Estudos de Manakins na Costa Rica e Panamá. Atua na conservação de aves migratórias no Hemisfério Ocidental há mais de 20 anos. E-mail: robpclay@gmail.com, Orcid: http://orcid.org/0000-0001-8928-5206

Geancarlo de Lima Merighi - Turismólogo, especialista em Administração de Turismo e de Lazer, e mestre em Desenvolvimento Local pela Universidade Católica Dom Bosco. Diretor de Desenvolvimento do Turismo e Mercado da Fundação de Turismo de Mato Grosso do Sul. E-mail: geantur@gmail.com, Orcid: http://orcid.org/0000-0002-3930-9246

Cleber José Rodrigues Alho - PhD. em Ecologia pela University of North Carolina at Chapel Hill (UNC), EE.UU. Professor titular aposentado da Universidade de Brasília-DF, professor orientador do Programa de Pós-graduação em Meio Ambiente e Desenvolvimento Regional da Universidade para o Desenvolvimento do Estado e da Região do Pantanal (UNIDERP), Campo Grande, MS. E-mail: alhocleber@gmail.com, Orcid: http://orcid.org/0000-0003-4569-5312 
